\title{
Accounting
}

\section{Information and analytical support system of enterprise competitiveness management}

\author{
Ruslan Lupak ${ }^{a^{*}}$, Marta Kunytska-Iliash ${ }^{b}$, Yaroslav Berezivskyi ${ }^{b}$, Natalia Nakonechna ${ }^{c}$, Liliya \\ Ivanova $^{\mathrm{d}}$ and Taras Vasyltsiv
}

\author{
${ }^{a}$ Lviv University of Trade and Economics, Ukraine \\ ${ }^{b}$ Stepan Gzhytskyi National University of Veterinary Medicine and Biotechnologies Lviv, Ukraine \\ ${ }^{c}$ Lviv State University of Internal Affairs, Ukraine \\ ${ }^{d}$ Lviv State University of Physical Culture of I. Boberskyy, Ukraine \\ eState Enterprise "Dolishniy Institute of Regional Research of NAS of Ukraine", Ukraine
}

\section{H R O N I C L E \\ A B S T R A C T}

\section{Article history:}

Received: January 14, 2021

Received in revised format:

April 122021

Accepted: April 20, 2021

Available online:

April 20, 2021

Keywords:

Competitive position

Potential of competitiveness

Analyzing methods

Consumer goods market

Enterprise management

\begin{abstract}
Under the conditions of intense competitive struggle, integrated assessment methods are gaining increasingly greater importance in the processes of information and analytical support of enterprise development management. Enterprise competitiveness is one of the most universal, and, consequently, methodological and applied features among such generalizing characteristics. However, almost all of the approaches used are characterized by both significant advantages and certain disadvantages as of the date. This study develops a system of information and analytical support for managing enterprise competitiveness in the market of fast moving consumer goods, where competition is near the highest. The author's approach for assessing the competitiveness status of enterprises is developed. For this purpose, a system of indicators is determined, which reveal comprehensively and systematically the main parameters of competitiveness according to its structural components, or subsystems: (1) personnel, (2) property, (3) commodity, (4) organizational. The peculiarity of the approach includes the combination of the method of enterprise position rating in the market, and expert survey, which ends with presentation of the results using the graphical method. Summarizing approbation of the developed methodological approach to the assessment of enterprise competitiveness status, the results allow to allocate the leader enterprises, enterprises of average level of competitiveness, enterprises of attack zones and lost opportunities, and outsider enterprises are obtained. The results include the possibility of implementing a new better and more comprehensive approach for analyzing the status of competitiveness of competing enterprises, which serves as a significant information and analytical basis for policy planning to strengthen the competitive position of businesses for the consumer goods market.
\end{abstract}

\section{Introduction}

As a specific feature of the market environment, competitiveness determines the basic parameters of functioning of enterprises in order to obtain maximum profit in accordance with the task of meeting consumer needs. The ability of the company's management to occupy a certain market niche in a certain period of time is a specific economic feature of its competitiveness and availability of competitive advantages. Market conditions of economic development of enterprises determine the need to

* Corresponding author

E-mail address: rycj555@gmail.com (R. Lupak) 
study competitiveness as a system of parameters for assessing the availability of competitive advantages and their effective use in the strategic area of management (Hjaila et al., 2017)). Development, use of a reasonable system of economic parameters corresponding to the content, subject and purpose for assessing the competitiveness of enterprises is a comprehensive and systemic task of diagnosing the availability of competitive advantages of business entities taking into account the joint impact of external and internal factors of the market environment (Ilyash et al., 2021; Falciola et al., 2020; Cetindamar \& Kilitcioglu, 2013). Theoretical bases for determination and systematization of parameters of the enterprise competitiveness assessment are characterized by a variety of author's positions. In particular, the assessment of the enterprise competitiveness is associated with:

- products (goods, works, services) competitiveness (Liu et al., 2021; Zhao et al., 2018);

- quality of consumer needs satisfaction (Berezivskyi, Zbarsky \& Zbarska (2021), Akben-Selcuk (2016));

- goodwill of business, its market strategy (Havlovska \& Pokotylova, etc. (2019), Sabatino (2016));

- efficiency of resource potential utilization (Nyurenberger et al., 2019; Meidute-Kavaliauskiené et al., 2014; Mathews, 2002);

- financial and economic stability and business activity (Ilyash et al., 2020, 2021; Ren \& Sun, 2020; Amir et al., 2016);

- innovations activity (Frolova et al., 2021; Hermundsdottir \& Aspelun, 2021; Yanrong \& Kang, 2011).

Basically, methods of assessing enterprise competitiveness involve determination of the in-house characteristics, breaking them down into separate groups according to various features. In some cases, external aspects of activity should be highlighted. It is typical for businesses to be dependent on trends in the domestic consumer market, which determines the need to take this aspect into account in assessing competitiveness (Yanchuk et al., 2016; Vasyltsiv \& Lupak, 2016). Pace of industry development is directly conditioned by the whole economic situation in the real sector of the economy. Such relationships create an environment to which business entities need to adapt in order to form a set of competitive advantages and achieve a sufficient level of competitiveness (Lupak et al., 2021; Karpenko, 2013). In such a way, the system of selection of criteria for assessing the competitiveness of business includes macroeconomic indicators, which importance is mainly formed at the account of the basic lines of business (Vlasiuk, 2016). At the same time, the relevant features determine the degree of economic security of the country, which is also advisable to take into account in the context of assessing the factors impacting the level of the enterprise competitiveness (Varnaliy et al., 2016). With the current globalization trends, a number of resources are of paramount importance, and it becomes possible to draw qualitative conclusions about the level of the enterprise competitiveness according to their availability. This refers to the ownership of information resources (technologies), access to which, on the one hand, is free and by no means limited, but, on the other hand, timeliness, completeness, etc. are of general importance for operations management (Yu et al., 2021; Chukhray et al., 2020; Kuzmin et al., 2020; Saeidi et al., 2019). Therefore, the information component holds a basic place in the procedures for assessing the enterprise competitiveness.

\section{Methodology}

\subsection{Determination of the enterprise competitiveness assessment algorithm}

In general, the basic enterprise competitiveness assessment algorithm is substantiated as a structural and logical pattern of the system of support and calculation of the integrated indicator of competitiveness level (Fig. 1). Formulation of the purpose of assessing the enterprise competitiveness ensures and details the strategy, tactics of economic and financial activities in a competitive environment. Substantiation of the purpose of competitiveness assessment ensures the functionality and integrity of the entire evaluation system, being a prerequisite for obtaining the forecast results of economic and financial activities. The purpose of assessment is further reflected in the structure of forecast indicators and parameters of the enterprise competitiveness. It is important to combine indicators of competitiveness assessment in terms of operations, tactical and strategic periods, which allows systematizing organizational and managerial measures for the formation and use of competitive advantages of the entity of competitive field. In this respect, the resource potential of the enterprise and reserves for its use during the implementation of competitive strategy are the prerequisites for the functionality of competitiveness assessment. It is advisable to use both, foreign economic information, in particular information on market conditions in the strategic economic management area, and domestic economic indicators of financial and economic activities. In order to assess the enterprise competitiveness, it is important to determine the range of competing companies, taking into account certain criteria features as follows:

- single intra-regional market of activity or its certain segment, the district of activity within particular territory;

- identity of business profile taking into account the variety, depth and consistency of the product range proposal;

- comparability of phases of the enterprises' life cycle;

- availability of access and equal opportunities for resource provision of the enterprise in the market environment.

It is important to take into account the form of ownership and organizational and legal form of business, as competitive advantages are a reflection of the ratio of debt capital to the facilities and results of labor. 


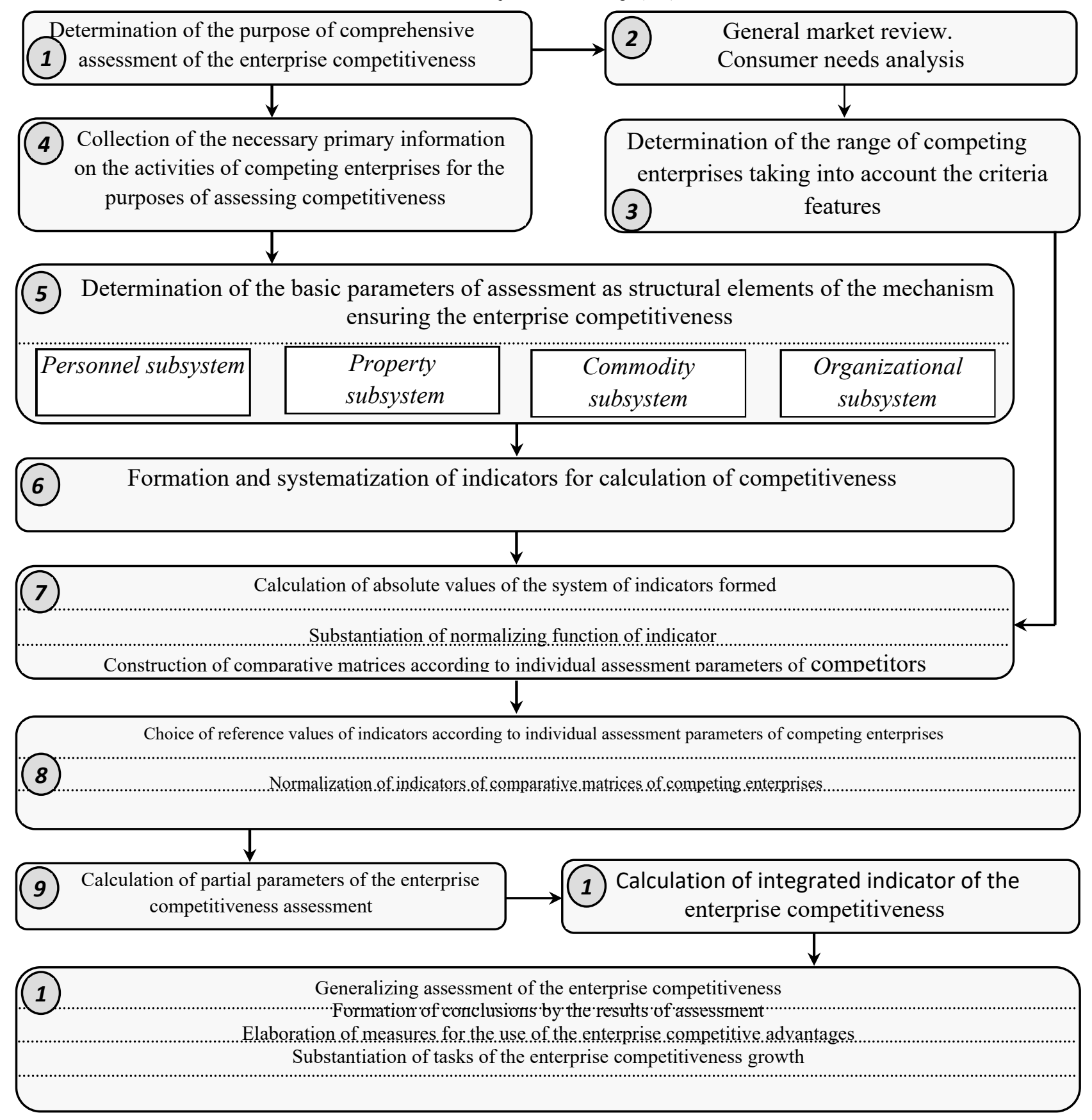

Fig. 1. Structural and logical pattern of the enterprise competitiveness comprehensive assessment

\subsection{Characteristics of the enterprise competitiveness assessment parameters system}

Structural elements of the mechanism of ensuring the enterprise competitiveness, in particular such subsystems as personnel, property, commodity, and organization have been chosen as the basic assessment parameters (Fig. 2).

The choice of subsystems is based on the principle of organization of internal and external business processes of the enterprise. However, the composition of competitiveness assessment subsystems may be increased. The number and structure of subsystems is determined by the information base of calculation and cumulative indicators of competitiveness assessment, which are interdependent. Comprehensiveness is an important principle of economic assessment of competitiveness, involving the use of a system of economic parameters and indicators of both partial and general content. Comprehensiveness of assessment is ensured by the consistency of calculations, in particular the combination of operations, tactical and strategic values, providing temporal and spatial relationship. In order to form reasonable appropriate cumulative indicators, it is necessary to be guided by 
the principle of quasimetric, whereby there is a limited choice of the number of priorities, qualitative, rational characteristics of assessment. At the same time, the structure of indicators is significantly influenced by the organization of accounting and reporting, the level of strategic analysis and planning in the economic and financial activities of the assessment object. Lines of research and cumulative indicators used reflect the purpose and strategic approach to the assessment and planning of competitiveness. The system of indicators should ensure the specificity of the assessment through the use of information-based characteristics of the competitive field. At the same time, the availability of information, in particular information on the financial and economic activities of competitors is insufficient, which requires additional study of the competitive environment.

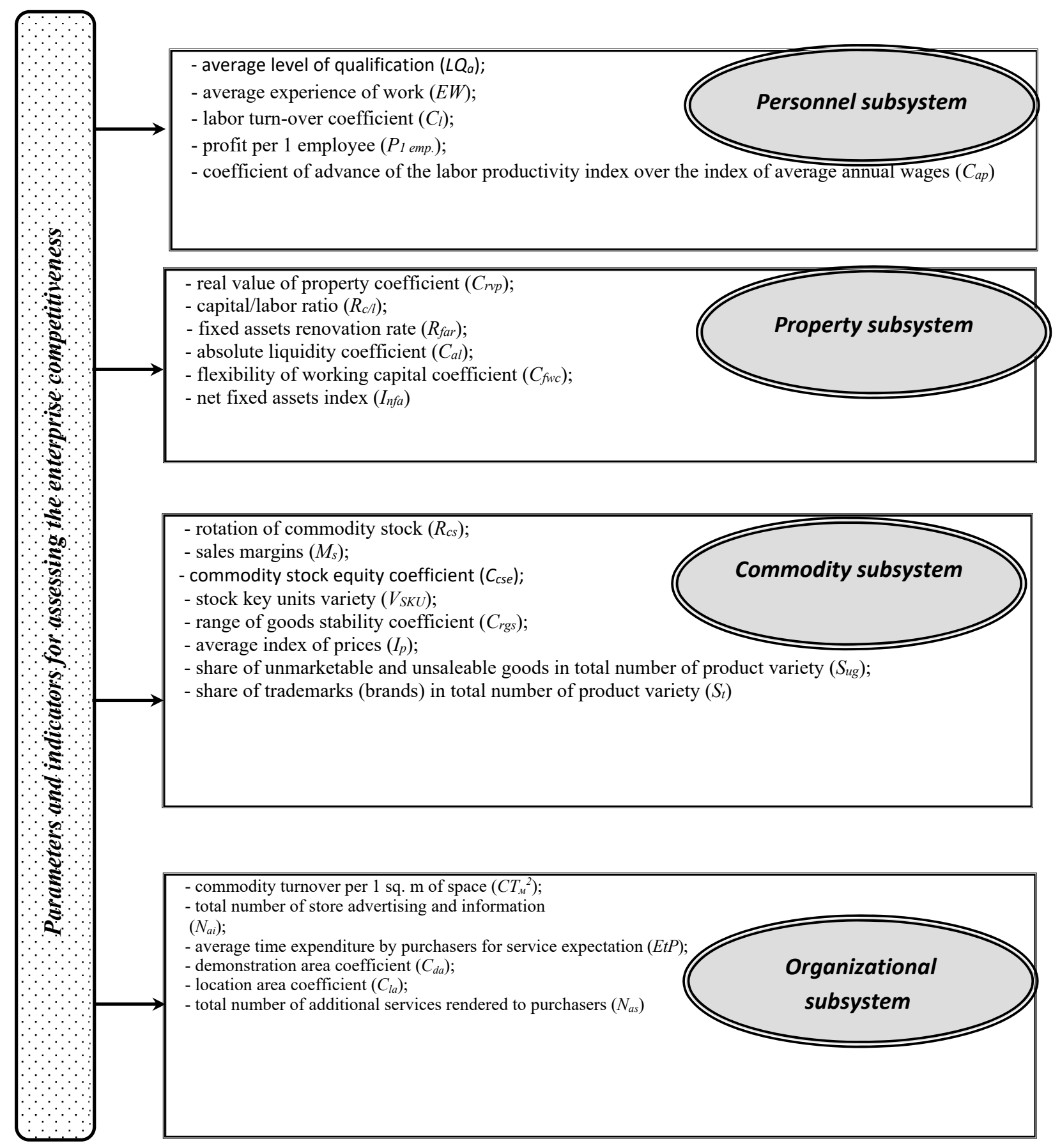

Fig. 2. Parameters and indicators for assessing the enterprise competitiveness

It is important that systematization of indicators for assessing the enterprise competitiveness corresponds to the features of absence of a close linear relationship between regression variables, or multicollinearity (Table A.1 of Appendix A). The 
correlation coefficient between the regression variables is less than 0.8 in absolute value, which confirms the level of the model objectivity, the reduction of the confidence interval and, in general, its practical significance for the economic system of the enterprise. At the same time, the information base of the study was the financial and statistical reporting of selected enterprises, which indicators were taken into account according to the statistically average values.

\subsection{Enterprise competitiveness status assessment methods}

It is suggested to group the obtained indicators of enterprise competitiveness assessment into comparative matrices, and to calculate the correlation ratios of actual indicators to the reference values. In this case, indicators should be normalized using formulas (1), (2):

- normalizing function $\left(\max \left(a_{i j}^{*}\right)\right)$ :

$$
\max \left(a_{i j}^{*}\right)=\frac{a_{i j}}{\max \left(a_{i j}\right)},
$$

- normalizing function $\left(\min \left(a_{i j}^{*}\right)\right)$ :

$$
\max \left(a_{i j}^{*}\right)=\frac{\min \left(a_{i j}\right)}{a_{i j}},
$$

where $a_{i j}$ is a value of indicator $j$ of enterprise $i$. To normalize economic indicators of competitiveness, one of the normalizing functions of maximization or minimization is used, depending on the trends of the indicator (function of maximization in case of increase, or function of minimization in case of decrease). According to the results of economic indicators, it is advisable to determine partial parameters of assessing the competitiveness of individual subsystems of the enterprise (formula (3)):

$$
Z_{i p}=\frac{\sum_{j=1}^{n} w_{j} \frac{a_{i j}}{a_{0 i j}}}{V_{i p} \cdot \sum_{j=1}^{n} w_{j}}
$$

where $Z_{i p}$ are partial values of parameter $p$ of enterprise $i$ competitiveness assessment $(i=1,2,3, \ldots, m)$; $w_{j}$ is a weight of indicator $j(j=1,2,3, \ldots, n)$; $a_{0 i j}$ is a reference value of indicator $j$ of enterprise $i$; $V_{i p}$ is a number of normalized indicators of parameter $p$ of enterprise $i$ competitiveness assessment. In accordance with the obtained results of partial parameters of assessment and determination of the relevant reference values of competitiveness of individual subsystems, calculation of integrated indicator of the enterprise competitiveness is suggested. In this respect, the indicators of assessing the enterprise competitiveness are characterized by the equal price of weight $(\mathrm{wj}=1)$. Generalized integrated assessment is the means of synthesis of essentially different indicators, differing in qualitative and quantitative features, which, by reference to specific features and degree of impact, form a generalized indicator of the enterprise competitiveness. It is the integrated indicator that characterizes the relative level of the enterprise competitiveness in comparison with other subjects of competition. Comparison of individual indicators of competitiveness is based not on absolute values, but on their relative variation, which provides an economic interpretation of the results. Bearing in mind such substantiations, the integrated indicator of the enterprise competitiveness should be calculated by the formula (4):

$$
I_{K C_{i}}=\sqrt{\sum_{p=1}^{k}\left(Z_{i p}-Z_{0 p}\right)^{2}},
$$

where $I_{K C i}$ is an integrated indicator of enterprise $i$ competitiveness; $p$ is a number of partial parameters of enterprise $i$ competitiveness assessment $(p=1,2,3, \ldots k) ; Z_{0 p}$ is a reference value of partial parameter $p$ of enterprise competitiveness assessment.Value of the integrated indicator of competitiveness, approaching the lowest number, characterizes the growth of the ranking position and competitive status of the enterprise in a competitive environment.

\section{Results and Discussion}

\subsection{Determination of the enterprises ranking positions}

Taking into account the above criteria feature of research and approbation of the suggested methodology of assessing competitiveness, enterprises of various forms of ownership of Ukraine, specializing in the sale of fast moving consumer goods have been selected for information modeling: 
- collectively-owned enterprises (consumer societies (Drohobych Town Consumer Society (№ 1), Medenychi Consumer Society (№ 2), Suburban Consumer Society (№ 3)) and Business Companies («Sofia» LLC (№ 4), «Ocean» LLC (№ 5));

- privately-owned enterprises (PE «1000 Little Buys Store» (№ 6), PE «Trade and Commercial Company» (№ 7)).

The enterprises selected occupy in their totality almost $40.0 \%$ of the goods turnover in the economic business area (territorial competitive environment). In accordance with the suggested methodology and determined totality of surveyed enterprises, their competitiveness was assessed (Table 1).

Table 1

Rating positions of the enterprises according to the integrated indicator of competitiveness in 2018-2020

\begin{tabular}{|c|c|c|c|c|c|c|}
\hline \multirow{2}{*}{ Enterprises } & \multicolumn{4}{|c|}{ Value of partial parameter $\left(Z_{i p}\right)$} & \multirow{2}{*}{$\begin{array}{l}\text { Integrated indicators of competitiveness } \\
\qquad\left(I_{K C i}\right)\end{array}$} & \multirow{2}{*}{ Ratings } \\
\hline & $Z_{i P S}$ & $Z_{i C S}$ & $Z_{i C S}$ & $Z_{\text {ios }}$ & & \\
\hline \multicolumn{7}{|c|}{ ( } \\
\hline 1 & 0,5170 & 0,4426 & 0,5101 & 0,5318 & 0,4578 & 3 \\
\hline 2 & 0,6979 & 0,1840 & 0,6887 & 0,4837 & 0,5974 & 4 \\
\hline 3 & 0,8216 & $-0,9383$ & 0,7279 & 0,6606 & 1,8101 & 7 \\
\hline 4 & 0,6422 & 0,6815 & 0,7334 & 0,6160 & 0,1987 & 1 \\
\hline 5 & 0,5667 & 0,5120 & 0,7097 & 0,4414 & 0,4057 & 2 \\
\hline 6 & 0,8397 & $-0,1999$ & 0,6541 & 0,6589 & 1,3870 & 6 \\
\hline 7 & 0,7353 & $-0,3957$ & 0,6186 & 0,6140 & 1,2453 & 5 \\
\hline \multicolumn{7}{|c|}{2019} \\
\hline 1 & 0,5963 & 0,4961 & 0,5857 & 0,5387 & 0,3292 & 4 \\
\hline 2 & 0,8599 & $-0,2233$ & 0,7109 & 0,6619 & 1,0049 & 7 \\
\hline 3 & 0,4536 & 0,5134 & 0,7712 & 0,5518 & 0,3968 & 6 \\
\hline 4 & 0,7118 & 0,6445 & 0,7074 & 0,5402 & 0,1848 & 1 \\
\hline 5 & 0,6240 & 0,6734 & 0,6660 & 0,5046 & 0,2715 & 3 \\
\hline 6 & 0,7481 & 0,3530 & 0,7613 & 0,6339 & 0,2650 & 2 \\
\hline 7 & 0,5854 & 0,4719 & 0,6642 & 0,5252 & 0,3517 & 5 \\
\hline \multicolumn{7}{|c|}{2020} \\
\hline 1 & 0,6109 & 0,4748 & 0,6102 & 0,4945 & 0,3393 & 6 \\
\hline 2 & 0,7536 & 0,4433 & 0,6388 & 0,5807 & 0,2729 & 5 \\
\hline 3 & 0,5136 & 0,5078 & 0,8180 & 0,5146 & 0,3441 & 7 \\
\hline 3 & 0,6720 & 0,6023 & 0,6415 & 0,6196 & 0,2152 & 3 \\
\hline 5 & 0,8081 & 0,6428 & 0,7074 & 0,6177 & 0,1028 & 2 \\
\hline 6 & 0,8112 & 0,6031 & 0,7449 & 0,6672 & 0,0791 & 1 \\
\hline 7 & 0,8454 & 0,5575 & 0,6754 & 0,4857 & 0,2167 & 4 \\
\hline
\end{tabular}

Partial values of competitiveness promotion parameters: $\boldsymbol{Z}_{i P S}-$ personnel subsystem; $\boldsymbol{Z}_{\boldsymbol{i} \text { CS }}-$ commodity subsystem; $\boldsymbol{Z}_{\boldsymbol{i P S}}-$ property subsystem; $Z_{i o s}$ - organizational subsystem

In 2018, the leadership area included enterprises № 4, № 5, № 1 (sequence according to the received rating); during 2020 the leadership positions changed dramatically (rating sequence: enterprises № 6, № 5, № 3). The main reason for the poor results of competitiveness of enterprises № 3, № 6, № 7 in 2018 is their overexposure to external borrowing, partial availability of effective financial mechanism in the use of working capital, insolvency, excess of current liabilities over current assets. Low competitive rating of cooperatively-owned enterprises (№ 1, № 2, № 3 ) is due to the inability to rationally accumulate their own resources, which requires improvement of their competition policy and appropriate use of advanced tools and instruments.

\subsection{Use of expert methods in integrated assessment of the enterprise competitiveness}

In order to systematize the impact of factors on the development of competitive environment and economic diagnosis of the competitive status of enterprises, an analytical method of expert assessments was chosen, based on the use of professional experience, intuition and imagination of specialists. It is the choice of experts that ensures the objectivity and representativeness of the assessment of organizational, economic, social and other aspects of the enterprise's competitiveness. Meanwhile, the degree of objectivity depends on the functional features, professional qualifications of experts and their participation in the enterprise management system. Accordingly, the expert group for assessing the competitiveness of enterprises included:

- employees of economic services of enterprises;

- employees of the management apparatus;

- employees of the state authorities;

- scientists researching aspects of competitiveness.

Delphi approach was used to systematize and process the assessments of experts, taking into account the functional features of the objects under study. Anonymity, feedback and grouping of answers according to this approach makes it possible to effectively form a representative expert group, organizationally prepare and evaluate, process the materials of questionnaires. In order to determine the impact of individual parameters on the range of effective expert assessment, the concordance coefficient (W) (formula (5)) was used. 


$$
W=\frac{\sum_{j=1}^{n} d_{j}^{2}}{\frac{1}{12} \cdot\left[m^{2} \cdot\left(n^{3}-n\right)-m \cdot \sum_{i=1}^{m} T_{i}\right]},
$$

where $d_{j}$ is a squared deviation of the sum of assessment parameters rank from their average value; $m$ is a number of experts; $n$ is a number of assessment parameters; $\sum_{i=1}^{n} T_{i}$ is a hypothetical sum of ranks, established by the experts under the condition of their consensus. Hypothetical sum of ranks as an intermediate calculation of concordance coefficient is determined according to the formula (6):

$$
T_{i}=\sum_{i=1}^{L}\left(t_{e}^{3}-t_{e}\right)
$$

where $L$ is a number of groups of connected (equal ranks); $t_{e}$ is a number of connected ranks in each group. The reported value of concordance coefficient of 0,604 suggests moderate degree of consensus between experts and sufficient reliability of obtained results. To assess the significance of concordance coefficient, it is important to calculate $X^{2}$ criterion (formula (7)).

$$
X^{2}=\frac{\sum_{j=1}^{m} d_{j}^{2}}{\frac{1}{12} \cdot\left[m \cdot n \cdot(n+1)-\frac{1}{n-1} \cdot \sum_{i=1}^{n} T_{i}\right]},
$$

After calculation of the value of $X^{2}$ criterion and its comparison with the tabular value of Pearson for $n$ - 1 degrees of freedom, the consensus of experts and the static significance of the concordance coefficient may be affirmed with a probability of $99.0 \%$. To summarize findings of the expert research of the enterprises' competitiveness, it is advisable to calculate the degree of agreement of expert assessments (Table 2).

Table 2

Matrix of expert assessments of the importance of factors of ensuring the enterprise competitiveness

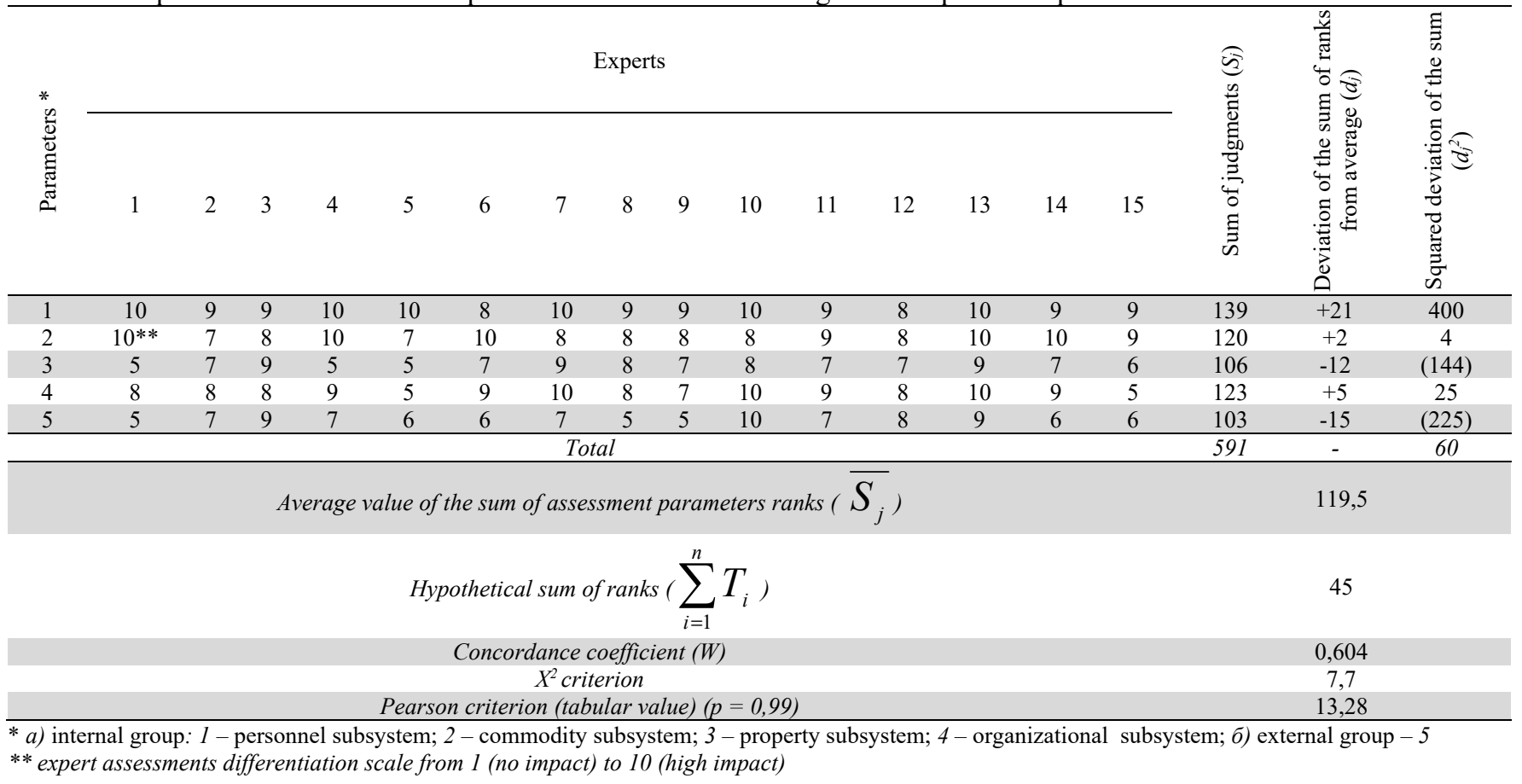

In accordance with the results of expert judgments and their consensus on the impact of factors on the enterprises competitiveness, it is advisable to calculate the relative importance of the assessment parameters. One of the methods of determining the competitiveness parameters rank is the calculation of statistical average and its normalization. Normalization is 
performed by dividing each result of statistical average by their sum. The results of the obtained values of calculation of the rank of systematized factors impacting the enterprises competitiveness are presented in Table 3.

Table 3

Relative importance of the enterprise's competitiveness factors

\begin{tabular}{|c|c|c|c|c|c|}
\hline \multirow{2}{*}{ Indicators } & \multicolumn{5}{|c|}{ Parameters* } \\
\hline & 1 & 2 & 3 & 4 & 5 \\
\hline Statistical average $\left(x_{n}\right)$ & 9,2667 & 8,5714 & 7,0667 & 8,2000 & 6,8667 \\
\hline Sum of statistical average $\left(\sum \overline{x_{n}}\right)$ & & & 39,9725 & & \\
\hline Rank of $n$ factor $\left(R_{n}\right)$ & 0,2319 & 0,2144 & 0,1768 & 0,2051 & 0,1718 \\
\hline Total estimate $\left(S_{R n}\right)$ & & & 1,0000 & & \\
\hline
\end{tabular}

* a) internal group: 1 - personnel subsystem; 2 - commodity subsystem; 3 - property subsystem; 4 - organizational subsystem; б) external group -5

Personnel subsystem (0.2319); commodity subsystem (0.2144); organizational subsystem (0.2051) are the most important parameters of assessment through the prism of the system of impact of factors on the enterprise competitiveness. Property subsystem (0.1768) is less important factor of impact. Impact of external factors on the enterprises' competitiveness is the least significant relative to the impact of other subsystems, and is characterized by parameter of 0.1718 . It should be noted that the difference between the first and last rank does not exceed 0.0601, which indicates the rationality of the choice, and high relevance of the parameters of assessing the business competitiveness. The next stage of analytical assessment of the competitive environment includes determination of a set of own ranks of systematized factors and formation of a matrix of group indicators of a particular parameter of the subsystem to ensure the enterprise competitiveness over a certain calendar period. It should be noted that indicators and parameters of integrated assessment of individual subsystems and competitiveness of the enterprise as a whole for 2018-2020 are the initial data for obtaining a consensus of experts (Table 1). The parametric single assessment of the enterprise's competitiveness by each systematized parameter over the analytical period is calculated according to the formula (8).

$$
a_{i j}=\frac{\sum_{i=1}^{m} K_{i j}}{m},
$$

where $a_{i j}$ is a value of single assessment of parameter $j$ of enterprise $i$; $K_{i j}$ is a value of single assessment by expert $m$ of parameter $j$ of enterprise $i$. According to the calculated rank of assessment parameters, total parametric indicator of competitiveness during the analytical period is determined for each enterprise (formula (9)).

$$
C_{i}=\sum_{i=1}^{n}\left(a_{i j} \cdot R_{j}\right) \text {, }
$$

where $C_{i}$ is a total parametric indicator of competitiveness assessment of enterprise $i$; $R_{j}$ is a rank of parameter $j$ of the enterprise competitiveness assessment. The enterprise competitiveness coefficient is calculated by normalizing the results of the total parametric indicator. The highest total assessment according to the determined parametric indicators will be taken as unity to characterize the position of the leader enterprise. As far as other enterprises are concerned, the competitiveness coefficient is calculated by the ratio of their total parametric indicator to the maximum value of such indicator of the leader enterprise (formula (10)).

$$
K_{K C_{i}}^{A}=\frac{C_{i}}{C_{i}^{\max }},
$$

where $K^{A}{ }_{K C i}$ is a coefficient of competitiveness of enterprise $i$; $C_{i}^{\max }$ is a maximum value of the total parametric indicator of competitiveness assessment of enterprise $i$. Gradational changes in the enterprise competitiveness coefficient should be noted as follows:

- if the competitiveness coefficient is equal to 1.0, it means that the enterprise is a leader and has an exceptionally strong competitive status;

- the range of 0.8-1.0 characterizes the candidate enterprise with a strong competitive position;

- the range of 0.5-0.7 characterizes the follower enterprise with an average competitive position;

- the range of 0.0-0.4 characterizes a newcomer enterprise with a weak competitive position.

The final stage of the analytical assessment of the enterprise competitiveness is the construction of a matrix of expert judgments on the formation of its competitive position in the market environment (Table 4). 
Table 4

Matrix of expert assessment of the enterprises' competitiveness in 2018-2020

\begin{tabular}{|c|c|c|c|c|c|c|c|c|c|c|c|c|c|c|c|c|c|c|}
\hline & & & & & & & & & & 2018 & & & & & & & & \\
\hline & & & & & Enterprises & & & & Factor & Concordance & $X^{2}$ & & netric indic & ors of the $\mathrm{e}$ & erprises co & petitivene & assessment & \\
\hline & & 1 & 2 & 3 & 4 & 5 & 6 & 7 & $\operatorname{ranks}\left(R_{i j}\right)$ & coefficient $(W)$ & criterion & 1 & 2 & 3 & 4 & 5 & 6 & 7 \\
\hline 存 & 1 & 6,0102 & 6,2009 & 6,2289 & 9,4277 & 7,9029 & 8,5040 & 7,2304 & 0,2319 & 0,408 & 36,72 & 1,3944 & 1,4386 & 1,4451 & 2,1872 & 1,8335 & 1,9729 & 1,6775 \\
\hline 然 & 2 & 8,2306 & 9,3119 & 8,9132 & 5,4532 & 7,6735 & 6,1220 & 6,2759 & 0,2144 & 0,526 & 47,36 & 1,7613 & 1,9927 & 1,9074 & 1,1670 & 1,6421 & 1,3101 & 1,3430 \\
\hline 跣 & 3 & 8,4208 & 8,7077 & 9,6765 & 6,4612 & 6,6275 & 5,8091 & 4,3308 & 0,1768 & 0,752 & 47,71 & 1,4905 & 1,5413 & 1,7127 & 1,1436 & 1,1731 & 1,0282 & 0,7666 \\
\hline 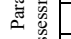 & 4 & 5,4170 & 6,7337 & 6,5675 & 9,3511 & 8,8127 & 7,5010 & 7,3518 & 0,2051 & 0,416 & 37,45 & 1,1105 & 1,3804 & 1,3463 & 1,9170 & 1,8066 & 1,5377 & 1,5071 \\
\hline : & 5 & 5,2024 & 5,9006 & 5,1021 & 7,7083 & 8,6125 & 7,7720 & 5,9181 & 0,1718 & 0,444 & 39,93 & 0,8948 & 1,0149 & 0,8776 & 1,3258 & 1,4814 & 1,3368 & 1,0179 \\
\hline & & Total & rametric & licator of & mpetitive & ss assessm & te $\left(C_{i j}\right)$ & & 1,0000 & & & 6,6515 & 7,3679 & 7,2892 & 7,7406 & 7,9366 & 7,1857 & 6,3121 \\
\hline & & & & & Com & titiveness & efficient & $\left.K_{K i}\right)$ & & & & 0,8381 & 0,9283 & 0,9184 & 0,9753 & 1,0000 & 0,9053 & 0,7953 \\
\hline & & & & & & Rat & & & & & & 6 & 3 & 4 & 2 & 1 & 5 & 7 \\
\hline & & & & & & & & & & 2019 & & & & & & & & \\
\hline & & & & & Enterprises & & & & Factor & Concordance & $X^{2}$ & & netric indic & ors of the $\mathrm{e}$ & erprises co & petitivene & assessment & \\
\hline & & 1 & 2 & 3 & 4 & 5 & 6 & 7 & $\operatorname{ranks}\left(R_{i j}\right)$ & coefficient $(W)$ & criterion & 1 & 2 & 3 & 4 & 5 & 6 & 7 \\
\hline & 1 & 6,2044 & 6,4448 & 5,5784 & 8,1280 & 9,6268 & 9,0671 & 6,6402 & 0,2319 & 0,519 & 46,71 & 1,4388 & 1,4945 & 1,2936 & 1,8849 & 2,2325 & 2,1027 & 1,5399 \\
\hline 号 & 2 & 6,1398 & 7,1229 & 7,0329 & 9,6055 & 4,7709 & 8,4580 & 6,5787 & 0,2144 & 0,539 & 48,51 & 1,3164 & 1,5271 & 1,5079 & 2,0594 & 1,0229 & 1,8134 & 1,4105 \\
\hline 宸 & 3 & 7,8936 & 9,0983 & 8,1911 & 6,6375 & 5,6448 & 5,6140 & 7,1929 & 0,1768 & 0,503 & 45,24 & 1,3956 & 1,6086 & 1,4482 & 1,1735 & 0,9980 & 0,9926 & 1,2717 \\
\hline$=0$ & 4 & 6,0022 & 5,6392 & 5,8133 & 8,0199 & 9,6068 & 9,4731 & 7,2704 & 0,2051 & 0,645 & 58,11 & 1,2311 & 1,1566 & 1,1923 & 1,6449 & 1,9704 & 1,9429 & 1,4912 \\
\hline$\stackrel{0}{0}$ & 5 & 5,1302 & 6,1295 & 4,6544 & 9,4153 & 7,7949 & 8,3912 & 6,3448 & 0,1718 & 0,618 & 55,62 & 0,8814 & 1,0530 & 0,7996 & 1,6175 & 1,3392 & 1,4416 & 1,0900 \\
\hline & & Total & rametric & licator of & mpetitive & ss assessm & t $\left(C_{i j}\right)$ & & 1,0000 & & & 6,2632 & 6,8399 & 6,2416 & 8,3802 & 7,5629 & 8,2932 & 6,8032 \\
\hline & & & & & Com & titiveness & efficient & & & & & 0,7474 & 0,8162 & 0,7448 & 1,0000 & 0,9025 & 0,9896 & 0,8118 \\
\hline & & & & & & Rat & & & & & & 7 & 4 & 6 & 1 & 3 & 2 & 5 \\
\hline & & & & & & & & & & 2020 & & & & & & & & \\
\hline & & & & & Enterprises & & & & Factor & Concordance & $X^{2}$ & & netric indic & ors of the $\mathrm{e}$ & erprises co & petitivene & assessment & \\
\hline & & 1 & 2 & 3 & 3 & 5 & 6 & 7 & $\operatorname{ranks}\left(R_{i j}\right)$ & coefficient $(W)$ & criterion & 1 & 2 & 3 & 4 & 5 & 6 & 7 \\
\hline & 1 & 5,5350 & 6,3109 & 5,8812 & 8,6025 & 9,0671 & 9,4072 & 7,1842 & 0,2319 & 0,530 & 47,71 & 1,2836 & 1,4635 & 1,3639 & 1,9949 & 2,1027 & 2,1815 & 1,6660 \\
\hline 然 & 2 & 5,4648 & 6,3448 & 6,3547 & 9,4504 & 8,4587 & 9,0045 & 5,7067 & 0,2144 & 0,611 & 55,19 & 1,1717 & 1,3603 & 1,3624 & 2,0262 & 1,8135 & 1,9306 & 1,2235 \\
\hline 票 & 3 & 8,1638 & 7,8546 & 9,1995 & 5,1481 & 6,2930 & 6,5857 & 6,3773 & 0,1768 & 0,501 & 44,88 & 1,4434 & 1,3887 & 1,6265 & 0,9102 & 1,1126 & 1,1644 & 1,1275 \\
\hline 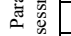 & 4 & 5,1278 & 5,6392 & 5,5435 & 7,9929 & 9,5419 & 8,9379 & 7,7107 & 0,2051 & 0,671 & 60,33 & 1,0517 & 1,1566 & 1,1370 & 1,6393 & 1,9570 & 1,8332 & 1,5815 \\
\hline$\stackrel{b}{a}$ & 5 & 5,4648 & 5,7067 & 5,0700 & 9,4823 & 8,4580 & 7,9291 & 7,2304 & 0,1718 & 0,766 & 68,92 & 0,9389 & 0,9804 & 0,8710 & 1,6291 & 1,4531 & 1,3622 & 1,2422 \\
\hline & & Total & rametric & licator of & mpetitive & ss assessm & it $\left(C_{i j}\right)$ & & 1,0000 & & & 5,8891 & 6,3495 & 6,3608 & 8,1997 & 8,4389 & 8,4718 & 6,8407 \\
\hline & & & & & & titiveness & efficient & & & & & 0,6951 & 0,7495 & 0,7508 & 0,9679 & 0,9961 & 1,0000 & 0,8075 \\
\hline & & & & & & Rat & & & & & & 7 & 6 & 5 & 3 & 2 & 1 & 4 \\
\hline
\end{tabular}

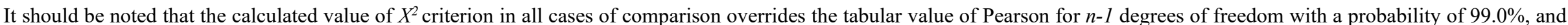

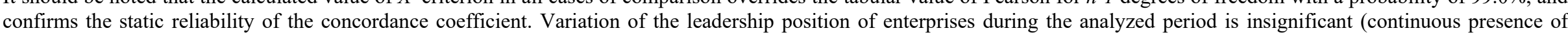

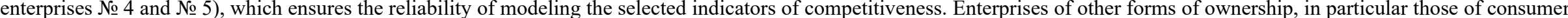

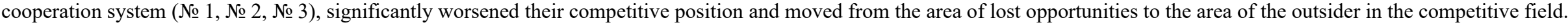

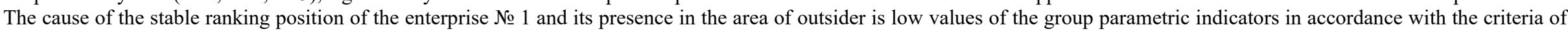
their high weight. 
Table 5

Matrix of graphical assessment of the enterprises' competitiveness in 2018-2020

\begin{tabular}{|c|c|c|c|c|c|c|c|c|c|c|c|c|c|c|c|c|}
\hline \multicolumn{17}{|c|}{2018} \\
\hline & & \multicolumn{7}{|c|}{ Parametric indicator of competitiveness assessment $\left(P_{i j}\right)$} & $\sin$ & \multicolumn{7}{|c|}{ Area of competitiveness polygon, square units $\left(S_{i}^{k}\right)$} \\
\hline & & 1 & 2 & 3 & 4 & 5 & 6 & 7 & $\left(R_{j} \times 360^{\circ}\right)$ & 1 & 2 & 3 & 4 & 5 & 6 & 7 \\
\hline \multirow{5}{*}{ 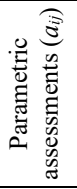 } & 1 & 1,3944 & 1,4386 & 1,4451 & 2,1872 & 1,8335 & 1,9729 & 1,6775 & 0,9930 & \multirow{5}{*}{4,2234} & \multirow{5}{*}{5,2142} & \multirow{5}{*}{5,0670} & \multirow{5}{*}{5,4099} & \multirow{5}{*}{5,7577} & \multirow{5}{*}{4,8405} & \multirow{5}{*}{3,5819} \\
\hline & 2 & 1,7613 & 1,9927 & 1,9074 & 1,1670 & 1,6421 & 1,3101 & 1,3430 & 0,9840 & & & & & & & \\
\hline & 3 & 1,4905 & 1,5413 & 1,7127 & 1,1436 & 1,1731 & 1,0282 & 0,7666 & 0,8988 & & & & & & & \\
\hline & 4 & 1,1105 & 1,3804 & 1,3463 & 1,9170 & 1,8066 & 1,5377 & 1,5071 & 0,9739 & & & & & & & \\
\hline & 5 & 0,8948 & 1,0149 & 0,8776 & 1,3258 & 1,4814 & 1,3368 & 1,0179 & 0,8527 & & & & & & & \\
\hline \multicolumn{10}{|c|}{ Competitiveness coefficient $\left(K_{K C i}^{G}\right)$} & 0,7335 & 0,9056 & 0,8800 & 0,9396 & 1,0000 & 0,8407 & 0,6221 \\
\hline \multirow{2}{*}{\multicolumn{17}{|c|}{ Rating }} \\
\hline & & & & & & & & & & & & & & & & \\
\hline & & \multicolumn{7}{|c|}{ Parametric indicator of competitiveness assessment $\left(P_{i j}\right)$} & $\sin$ & \multicolumn{7}{|c|}{ Area of competitiveness polygon, square units $\left(S_{i}^{k}\right)$} \\
\hline & & 1 & 2 & 3 & 4 & 5 & 6 & 7 & $\left(R_{j} \times 360^{\circ}\right)$ & 1 & 2 & 3 & 4 & 5 & 6 & 7 \\
\hline \multirow{5}{*}{ 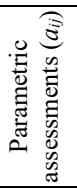 } & 1 & 1,4388 & 1,4945 & 1,2936 & 1,8849 & 2,2325 & 2,1027 & 1,5399 & 0,9930 & \multirow{5}{*}{3,6184} & \multirow{5}{*}{4,2053} & \multirow{5}{*}{3,8617} & \multirow{5}{*}{6,5648} & \multirow{5}{*}{4,8956} & \multirow{5}{*}{6,2753} & \multirow{5}{*}{4,1969} \\
\hline & 2 & 1,3164 & 1,5271 & 1,5079 & 2,0594 & 1,0229 & 1,8134 & 1,4105 & 0,9840 & & & & & & & \\
\hline & 3 & 1,3956 & 1,6086 & 1,4482 & 1,1735 & 0,9980 & 0,9926 & 1,2717 & 0,8988 & & & & & & & \\
\hline & 4 & 1,2311 & 1,1566 & 1,1923 & 1,6449 & 1,9704 & 1,9429 & 1,4912 & 0,9739 & & & & & & & \\
\hline & 5 & 0,8814 & 1,0530 & 0,7996 & 1,6175 & 1,3392 & 1,4416 & 1,0900 & 0,8527 & & & & & & & \\
\hline \multicolumn{10}{|c|}{ Competitiveness coefficient $\left(K_{K C i}^{G}\right)$} & 0,5512 & 0,6406 & 0,5882 & 1,0000 & 0,7457 & 0,9559 & 0,6393 \\
\hline \multirow{2}{*}{\multicolumn{17}{|c|}{ Rating }} \\
\hline & & & & & & & & & & & & & & & & \\
\hline & & \multicolumn{7}{|c|}{ Parametric indicator of competitiveness assessment $\left(P_{i j}\right)$} & & & Are & competit & ess polyg & square un & $\left(S_{i}^{k}\right)$ & \\
\hline & & 1 & 2 & 3 & 4 & 5 & 6 & 7 & $\left(R_{j} \times 360^{\circ}\right)$ & 1 & 2 & 3 & 4 & 5 & 6 & 7 \\
\hline & 1 & 1,2836 & 1,4635 & 1,3639 & 1,9949 & 2,1027 & 2,1815 & 1,6660 & 0,9930 & & & & & & & \\
\hline 番 & 2 & 1,1717 & 1,3603 & 1,3624 & 2,0262 & 1,8135 & 1,9306 & 1,2235 & 0,9840 & & & & & & & \\
\hline 苛 & 3 & 1,4434 & 1,3887 & 1,6265 & 0,9102 & 1,1126 & 1,1644 & 1,1275 & 0,8988 & 3,1315 & 3,7985 & 3,5806 & 4,4241 & 6,5036 & 6,6449 & 6,2387 \\
\hline हुँ & 4 & 1,0517 & 1,1566 & 1,1370 & 1,6393 & 1,9570 & 1,8332 & 1,5815 & 0,9739 & 3,10 & 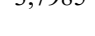 & 3,0000 & $4,72+11$ & 0,000 & $0,0+7$ & , \\
\hline $\begin{array}{r}0 \\
0 \\
0 \\
\vdots \\
\end{array}$ & 5 & 0,9389 & 0,9804 & 0,8710 & 1,6291 & 1,4531 & 1,3622 & 1,2422 & 0,8527 & & & & & & & \\
\hline & & & & ompetiti & s coeffici & $\left(K_{K C i}^{G}\right)$ & & & & 0,4713 & 0,5716 & 0,5388 & 0,6658 & 0,9787 & 1,0000 & 0,9389 \\
\hline & & & & & Rating & & & & & 7 & 6 & 5 & 4 & 2 & 1 & 3 \\
\hline
\end{tabular}


3.3. Graphical representation of the results of using the expert approach to the integrated assessment of the enterprise competitiveness

It is important to graphically represent the level of competitive struggle and the results of analytical assessment of the enterprises' competitiveness using a polygon in the form of calculation of the corresponding diagram area. If we draw axes at equal angles indicating the assessment parameter on each of them, the area of the competitiveness polygon may be calculated by the formula (11):

$$
S_{i}^{K}=\frac{1}{2} \sum_{i=1}^{n} P_{i j} \cdot P_{i j} \sin \left(R_{j} \cdot 360^{0}\right)
$$

where $S_{i}^{K}$ is an area of the competitiveness polygon of enterprise $i ; P_{i j}$ is a parametric indicator of assessment of parameter $j$ of enterprise $i$;

According to the assessment methodology, the competitiveness coefficient by the graphical method is calculated similarly to the analytical method, while the area of the enterprise competitiveness polygon is the calculation indicator (formula 12):

$$
K C_{K C_{i}}^{G}=\frac{S_{i}^{K}}{S_{i \max }^{K}},
$$

where $K^{G}{ }_{K C i}$ is a competitiveness coefficient of enterprise $i ; S_{i}^{K}$ max is a maximum value of the area of the competitiveness polygon of enterprise $i$. Calculation of the area of the enterprise competitiveness polygon (Table 5), graphical interpretation of the obtained results in the form of assessment figure (Fig. 3) notably simplifies the characteristics of the competitive field and the ranking positions of the competing subjects.

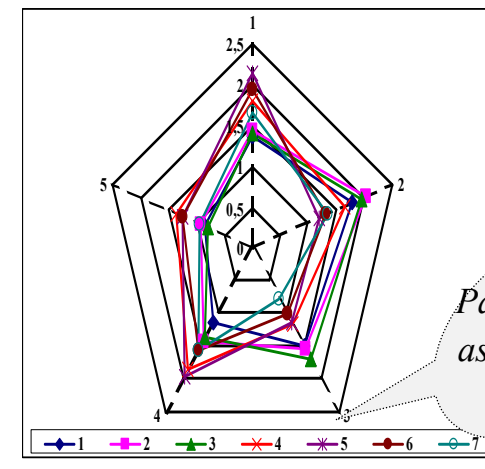

2018

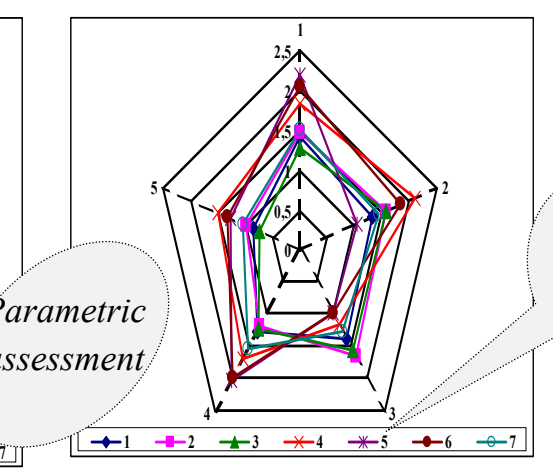

2019

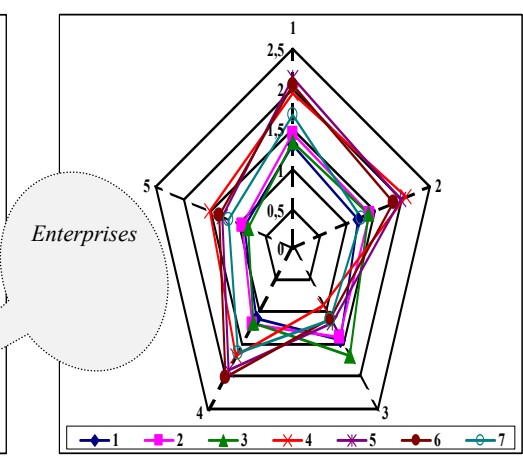

2020

Fig. 3. Enterprises' competitiveness polygons in 2018-2020

\subsection{Comparative characteristics of the enterprise competitiveness integrated assessment methods}

The results of graphical and analytical assessments of the enterprises competitiveness are generally identical, which reflects the reliability of the obtained assessment information (Table 6). However, the indicators of the competitiveness rating, calculated with the use of the expert method, and the indicators of the proposed methodological approach contain some differences, because:

- expert assessment reflects, as a rule, the marketing situation in the competitive field without reference to the peculiarities of resource provision, factors of organizational and managerial influence;

- the proposed methodological approach reflects the system of indicators and parameters in accordance with the research and statistical information support, which reliability and comparability is debatable in current economic environment.

\section{Conclusions}

Insufficient degree of readiness of some experts to take comprehensive account of both external and internal factors of impact on business competitiveness is one of the causes of differences between the results of expert assessment and the proposed methodology. In particular, experts do not fully take into account high dependence of some enterprises on external sources of financial resources formation (2018: enterprises № 5, № 6, 2019: enterprise № 5), which is confirmed by the indicators that reflect the generalized results of assessing the enterprises competitiveness according to the above two methods. Some expert assessments do not take into account the importance of the financial component of competitiveness, in particular the productivity of assets, costs, revenues, indicators of financial stability, solvency and investment 
attractiveness of competitors (2018: enterprise № 3, 2019: enterprise № 2, 2020: enterprises № 3, № 1). Also, the experts had insufficient regard to the efficiency of using the competitive potential of enterprises (2018: enterprise № 1, 2019: enterprise № 2, 2020: enterprises № 2). Another disadvantage of expert assessment is insufficient degree of consideration of the dynamics of the enterprises' competitiveness, in particular in terms of individual providing subsystems. Instead, a comprehensive coverage of economic processes, synthesis of indicators and their compliance with competition conditions and market dynamics of demand for fast moving consumer goods is a common feature in the use of the above methodological approaches to assessing the enterprises competitiveness. The identity of leadership positions in the analytical period, calculated by both the expert method of assessment and the proposed methodological approach is the matter of principle. In general, practical use of the determined assessment methods reflects the multivariance of competitiveness calculations and the choice of optimal ones. Also, such calculations comply with the principles of multivariance, optimality, consistency, making it possible to comprehensively take into account the indicators and parameters of subsystems of competitiveness, to systematize the relevant interrelations in its assessment. Certain universality of the conducted calculations of indicators of competitiveness that allows conducting them with regard to functional features of modeling of the enterprises' competitive strategies is also worth noting.

Table 6

Comparative table of the results of using the enterprises competitiveness assessment methodological approaches in 20182020

\begin{tabular}{|c|c|c|c|c|c|}
\hline \multirow{3}{*}{ 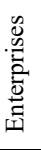 } & \multirow{2}{*}{\multicolumn{2}{|c|}{ Proposed methodological approach }} & \multicolumn{2}{|c|}{ Expert method of assessment } & \multirow[b]{3}{*}{ 点 } \\
\hline & & & \multirow[b]{2}{*}{ Competitiveness coefficient $\left(K_{K C i}^{A}\right)$} & Graphical assessment & \\
\hline & $\begin{array}{l}\text { Integrated indicator of competitiveness ( } \\
\left.\qquad I_{K C i}\right)\end{array}$ & $\stackrel{00}{\stackrel{\Xi}{\overparen{\Xi}}}$ & & $\begin{array}{l}\text { Competitiveness coefficient } \\
\qquad\left(K_{K C i}^{G}\right)\end{array}$ & \\
\hline \multicolumn{6}{|c|}{2018} \\
\hline 1 & 0,4578 & 3 & 0,8381 & 0,7335 & 6 \\
\hline 2 & 0,5974 & 4 & 0,9283 & 0,9056 & 3 \\
\hline 3 & 1,8101 & 7 & 0,9184 & 0,8800 & 4 \\
\hline 4 & 0,1987 & 1 & 0,9753 & 0,9396 & 2 \\
\hline 5 & 0,4057 & 2 & 1,0000 & 1,0000 & 1 \\
\hline 6 & 1,3870 & 6 & 0,9053 & 0,8407 & 5 \\
\hline 7 & 1,2453 & 5 & 0,7953 & 0,6221 & 7 \\
\hline \multicolumn{6}{|c|}{2019} \\
\hline 1 & 0,3292 & 4 & 0,7474 & 0,5512 & 7 \\
\hline 2 & 1,0049 & 7 & 0,8162 & 0,6406 & 4 \\
\hline 3 & 0,3968 & 6 & 0,7448 & 0,5882 & 6 \\
\hline 4 & 0,1848 & 1 & 1,0000 & 1,0000 & 1 \\
\hline 5 & 0,2715 & 3 & 0,9025 & 0,7457 & 3 \\
\hline 6 & 0,2650 & 2 & 0,9896 & 0,9559 & 2 \\
\hline 7 & 0,3517 & 5 & 0,8118 & 0,6393 & 5 \\
\hline \multicolumn{6}{|c|}{2020} \\
\hline 1 & 0,3393 & 6 & 0,6951 & 0,4713 & 7 \\
\hline 2 & 0,2729 & 5 & 0,7495 & 0,5388 & 6 \\
\hline 3 & 0,3441 & 7 & 0,7508 & 0,5716 & 5 \\
\hline 4 & 0,2152 & 3 & 0,9679 & 0,6658 & 4 \\
\hline 5 & 0,1028 & 2 & 0,9961 & 0,9787 & 2 \\
\hline 6 & 0,0791 & 1 & 1,0000 & 1,0000 & 1 \\
\hline 7 & 0,2167 & 4 & 0,8075 & 0,9389 & 3 \\
\hline
\end{tabular}

\section{References}

Akben-Selcuk, E. (2016). Factors affecting firm competitiveness: Evidence from an emerging market. International Journal of Financial Studies, 4(2), 1-10. https://doi.org/10.3390/ijfs4020009.

Amir, A., Auzair, S., \& Amiruddin, R. (2016). Cost Management, Entrepreneurship and Competitiveness of Strategic Priorities for Small and Medium Enterprises. Procedia - Social and Behavioral Sciences, 219, 84-90. https://doi.org/10.1016/j.sbspro.2016.04.046.

Berezivskyi, Y., Zbarsky, V., \& Zbarska A. Integral evaluation as the basis of analytical support for managing the competitiveness of socially-oriented retailers. Accounting, 7(4), 825-836. https://doi.org/ 10.5267/j.ac.2021.2.001.

Cetindamar, D., \& Kilitcioglu, H. (2013). Measuring the competitiveness of a firm for an award system. Competitiveness Review, 23(1), 7-22. https://doi.org/10.1108/10595421311296597.

Chukhray, N., Shakhovska, N., Mrykhina, O., Bublyk, M., \& Lisovska, L. (2020) Methodical Approach to Assessing the Readiness Level of Technologies for the Transfer. Advances in Intelligent Systems and Computing IV: CSIT 2019, Springer nature Switzerland AG, 259-282. https://doi.org/10.1007/978-3-030-33695-0_19.

Falciola, J., Jansen, M., \& Rollo, V. (2020). Defining firm competitiveness: A multidimensional framework. World Development, 129, 104857. https://doi.org/10.1016/j.worlddev.2019.104857.

Frolova, L., Zhadko, K., Ilyash, O., Yermak, S., \& Nosova, T. (2021). Model for opportunities assessment to increase the enterprise innovation activity. Business: Theory and Practice, 22(1), 1-11. https://doi.org/10.3846/btp.2021.13273. 
Havlovska, N., Pokotylova, V., Korpan, O., Rudnichenko, Ye., \& Sokyrnyk, I. (2019). Modeling of the process of functioning of the mechanism of economic security of foreign economic activity of enterprise taking into account weak signals and identification of risks and threats. International Journal of Scientific \& Technology Research, 8(12), 22162522.

Hermundsdottir, F., \& Aspelun, A. (2021). Sustainability innovations and firm competitiveness: A review. Journal of Cleaner Production, 280(1), 124715. https://doi.org/10.1016/j.jclepro.2020.124715.

Hjaila, K., Puigjaner, L., Laínez, J., \& Espuña, A. (2017). Integrated game-theory modelling for multi enterprise-wide coordination and collaboration under uncertain competitive environment. Computers \& Chemical Engineering, 98, 209235. https://doi.org/10.1016/j.compchemeng.2016.11.041.

Ilyash, O., Vasyltsiv, T., Lupak, R., \& Hetmanskyi, V. (2021). Models of efficiency of functioning in trading enterprises under conditions of economic growth. Bulletin of Geography. Socio-economic Series, 51, 7-24. http://doi.org/10.2478/bog-2021-0001.

Ilyash, O., Yildirim, O., Doroshkevych, D., Smoliar, L., Vasyltsiv, T., \& Lupak, R. (2020). Evaluation of enterprise investment attractiveness under circumstances of economic development. Bulletin of Geography. Socio-economic Series, 47, 95-113. http://doi.org/10.2478/bog-2020-0006.

Karpenko, O. (2013). Conceptual Bases Of Formation And Functioning Of Innovation Clusters. Actual Problems of Economics, 12(150), 71-78.

Kuzmin, O., Bublyk, M., Shakhno, A., Korolenko O., \& Lashkun H. (2020). Innovative development of human capital in the conditions of globalization. E3S Web of Conferences, 166, 13011. https://doi.org/10.1051/e3sconf/202016613011.

Liu Z., Qin, C.-X., \& Zhang, Y.-J. (2021). Mining product competitiveness by fusing multisource online information. Decision Support Systems, 143, 113477. https://doi.org/10.1016/j.dss.2020.113477.

Lupak, R., Boiko, R., Kunytska-Iliash, M., \& Vasyltsiv, T. (2021). State Management of Import Dependency and State's Economic Security Ensuring: New Approaches to Evaluating and Strategizing. Accounting, 7(4), 855-864. https://doi.org/10.5267/j.ac.2021.1.023.

Mathews, J. A. (2002). Competitive advantages of the latecomer firm: A resource-based account of industrial catch-up strategies. Asia Pacific Journal of Management, 19, 467-488. https://doi.org/10.1023/A:1020586223665.

Meidutè-Kavaliauskienė, I., Vasiliauskas, A., \& Zinkevičiūtė, V. (2014). Securing Enterprises Competitive Advantage through the Management of Components of Distribution System. Procedia-Social and Behavioral Sciences, 110, 353360. https://doi.org/10.1016/j.sbspro.2013.12.879.

Nyurenberger, L., Sewruikov, I., Sevostyanova, O., Shchetinina, N., Leushina, O., \& Varyuha, T. (2019). Actual Aspects of Ensuring Strategic Competitiveness in Commerce. Atlantis Press "New Silk Road: Business Cooperation and Prospective of Economic Development” (NSRBCPED 2019). https://doi.org/10.2991/aebmr.k.200324.067.

Ren, J., Sun, H., Xu, G., \& Hou, D. (2020). Prediction on the competitive outcome of an enterprise under the adjustment mechanism. Applied Mathematics and Computation, 372, 124969. https://doi.org/10.1016/j.amc.2019.124969.

Sabatino, M. (2016). Economic crisis and resilience: Resilient capacity and competitiveness of the enterprises. Journal of Business Research, 69(5), 1924-1927. https://doi.org/10.1016/j.jbusres.2015.10.081.

Saeidi, P., Saeidi, S., Sofian, S., Nilashi, M., \& Mardani, A. (2019). The impact of enterprise risk management on competitive advantage by moderating role of information technology. Computer Standards \& Interfaces, 63, 67-82. https://doi.org/10.1016/j.csi.2018.11.009.

Varnaliy, Z., Onishchenko, S., \& Masliy, A. (2016). Threat prevention mechanisms of Ukraine's economic security. Economic Annals-XXI, 159(5-6), 20-24. https://doi.org/10.21003/ea.V159-04.

Vasyltsiv, T., \& Lupak, R. (2016). Strategic priorities of state structural policy of import substitution in Ukraine. Actual Problems of Economics, 1(175), 52-60.

Vlasiuk, O. (2016). System transformations of the national economy: challenges and expectations. University of Economy Publishing House, Bydgoszcz.

Yanchuk, A., Klemparskiy, M., \& Zaverbnyy, A. (2016). Modern trends of development of shadow economy and methods of public policy of counteraction, Scientific bulletin of Polissia, 4(8), 51-56.

Yanrong, W., \& Kang, L. Y. (2011). Evaluation on the Competitiveness of High-tech Entrepreneurial Enterprises. Energy Procedia, 5, 684-689. https://doi.org/10.1016/j.egypro.2011.03.121.

Yu, G., Li, W., \& Zhou, X. (2021). An realistic study on the assessment system of international competitiveness of service trade using fuzzy-analytic network process. Journal of Intelligent \& Fuzzy Systems, 41, 1-10. https://doi.org/10.3233/JIFS-189642.

Zhao, M., Dong, C., \& Cheng, T. C. E. (2018). Quality disclosure strategies for small business enterprises in a competitive marketplace. European Journal of Operational Research, 270(1), 218-229. https://doi.org/10.1016/j.ejor.2018.03.030. 
Table A 1

Correlation matrix

\begin{tabular}{|c|c|c|c|c|c|c|c|c|c|c|c|c|c|c|c|c|c|c|c|c|c|c|c|c|c|}
\hline$L Q_{a}$ & $E W$ & $C_{l}$ & $P_{1 \text { emp. }}$ & $C_{a p}$ & $C_{r v p}$ & $R_{c / l}$ & $R_{f a r}$ & $C_{a l}$ & $C_{f w c}$ & $I_{n f a}$ & $R_{c s}$ & $M_{S}$ & $C_{c s e}$ & $V_{S K U}$ & $C_{r g s}$ & $I_{p}$ & $S_{u g}$ & $S_{t}$ & $C T_{M}{ }^{2}$ & $N_{a i}$ & $E t P$ & $C_{d a}$ & $C_{l a}$ & $N_{a s}$ & \\
\hline 1,0000 & & & & & & & & & & & & & & & & & & & & & & & & & $L Q_{a}$ \\
\hline$-0,5217$ & 1,0000 & & & & & & & & & & & & & & & & & & & & & & & & $E W$ \\
\hline 0,4842 & $-0,3959$ & 1,0000 & & & & & & & & & & & & & & & & & & & & & & & $C_{l}$ \\
\hline$-0,0995$ & $-0,2132$ & $-0,3228$ & 1,0000 & & & & & & & & & & & & & & & & & & & & & & $P_{1 \mathrm{emp}}$ \\
\hline$-0,0538$ & 0,4446 & $-0,1533$ & 0,4293 & 1,0000 & & & & & & & & & & & & & & & & & & & & & $C_{a p}$ \\
\hline$-0,6171$ & 0,5288 & $-0,6821$ & 0,4618 & 0,2558 & 1,0000 & & & & & & & & & & & & & & & & & & & & $C_{r v p}$ \\
\hline$-0,5359$ & 0,1868 & $-0,8384$ & 0,7369 & 0,4334 & 0,5583 & 1,0000 & & & & & & & & & & & & & & & & & & & $R_{c / l}$ \\
\hline$-0,4801$ & $-0,1798$ & $-0,5317$ & 0,4959 & $-0,4951$ & 0,2918 & 0,4298 & 1,0000 & & & & & & & & & & & & & & & & & & $R_{f a r}$ \\
\hline$-0,2360$ & $-0,2607$ & $-0,0191$ & 0,4702 & 0,4258 & 0,3903 & 0,3145 & $-0,1924$ & 1,0000 & & & & & & & & & & & & & & & & & $C_{a l}$ \\
\hline 0,1770 & 0,1830 & $-0,4015$ & $-0,0436$ & $-0,2878$ & $-0,1589$ & 0,0791 & 0,3075 & $-0,8773$ & 1,0000 & & & & & & & & & & & & & & & & $C_{f w c}$ \\
\hline 0,5166 & $-0,5709$ & 0,1503 & 0,0426 & $-0,2563$ & $-0,7897$ & 0,0274 & 0,1776 & $-0,1259$ & 0,1757 & 1,0000 & & & & & & & & & & & & & & & $I_{n f a}$ \\
\hline 0,2506 & 0,1573 & 0,5451 & $-0,9713$ & $-0,3451$ & $-0,5593$ & $-0,7978$ & $-0,5875$ & $-0,3035$ & $-0,1401$ & 0,0558 & 1,0000 & & & & & & & & & & & & & & $R_{c s}$ \\
\hline$-0,5318$ & 0,4822 & 0,0261 & $-0,7854$ & $-0,5014$ & $-0,1441$ & $-0,2923$ & 0,2131 & $-0,4791$ & 0,1309 & $-0,1706$ & 0,5765 & 1,0000 & & & & & & & & & & & & & $M_{s}$ \\
\hline 0,0181 & $-0,0721$ & $-0,8139$ & 0,5591 & 0,1438 & 0,2913 & 0,7319 & 0,3471 & $-0,0494$ & 0,5283 & 0,3309 & $-0,5883$ & $-0,5293$ & 1,0000 & & & & & & & & & & & & $C_{c s e}$ \\
\hline 0,4486 & $-0,1208$ & 0,5768 & $-0,8232$ & $-0,5897$ & $-0,7104$ & $-0,8567$ & $-0,2284$ & $-0,7125$ & 0,3624 & 0,2546 & 0,7805 & 0,5278 & $-0,4770$ & 1,0000 & & & & & & & & & & & $V_{S K U}$ \\
\hline$-0,3764$ & 0,4588 & $-0,1854$ & $-0,1624$ & 0,4699 & 0,1685 & 0,3385 & $-0,4365$ & 0,5349 & $-0,8415$ & $-0,1644$ & 0,2670 & 0,0842 & $-0,0162$ & $-0,3799$ & 1,0000 & & & & & & & & & & $C_{r g s}$ \\
\hline 0,2466 & 0,2890 & 0,2741 & $-0,8130$ & $-0,1812$ & $-0,6263$ & $-0,4821$ & $-0,3603$ & $-0,7470$ & 0,4395 & 0,3298 & 0,7643 & 0,6390 & $-0,1604$ & 0,7785 & 0,0997 & 1,0000 & & & & & & & & & $I_{p}$ \\
\hline 0,0467 & 0,0112 & 0,0081 & $-0,7398$ & $-0,6395$ & $-0,6836$ & $-0,3177$ & 0,1492 & $-0,7171$ & 0,3816 & 0,4821 & 0,6425 & 0,6973 & 0,0313 & 0,7135 & $-0,0589$ & 0,7896 & 1,0000 & & & & & & & & $S_{u g}$ \\
\hline$-0,0589$ & $-0,4415$ & 0,3165 & $-0,1269$ & $-0,4994$ & $-0,1188$ & $-0,2964$ & 0,1044 & 0,6151 & $-0,7653$ & $-0,1032$ & 0,2355 & 0,1370 & $-0,5314$ & 0,0142 & 0,1726 & $-0,3816$ & 0,0793 & 1,0000 & & & & & & & $S_{t}$ \\
\hline$-0,1797$ & $-0,4080$ & $-0,5019$ & 0,4486 & $-0,5917$ & 0,3959 & 0,2548 & 0,7257 & 0,1959 & 0,0436 & $-0,0883$ & $-0,5266$ & $-0,1066$ & 0,2954 & $-0,2517$ & $-0,4831$ & $-0,6679$ & $-0,1188$ & 0,4273 & 1,0000 & & & & & & $C T_{M}{ }^{2}$ \\
\hline$-0,1604$ & 0,5569 & $-0,2446$ & 0,2548 & 0,5401 & 0,3928 & 0,2872 & $-0,0171$ & $-0,4710$ & 0,6151 & $-0,3624$ & $-0,4041$ & $-0,1157$ & 0,1705 & $-0,1553$ & $-0,2629$ & 0,1731 & $-0,3421$ & $-0,8891$ & $-0,2691$ & 1,0000 & & & & & $N_{a i}$ \\
\hline 0,2436 & $-0,3999$ & $-0,3815$ & 0,7785 & 0,1597 & 0,4669 & 0,4365 & 0,5108 & 0,5603 & $-0,1674$ & $-0,0254$ & $-0,6395$ & $-0,8516$ & 0,5978 & $-0,6526$ & $-0,0497$ & $-0,7369$ & $-0,6071$ & 0,0914 & 0,5217 & $-0,1771$ & 1,0000 & & & & $E t P$ \\
\hline$-0,3075$ & $-0,1183$ & $-0,1614$ & $-0,1267$ & $-0,6151$ & 0,4495 & $-0,1614$ & 0,1969 & 0,3299 & $-0,4847$ & $-0,5004$ & 0,1934 & 0,2436 & $-0,1956$ & $-0,0538$ & 0,1233 & $-0,4405$ & $-0,1217$ & 0,7227 & 0,6961 & $-0,5197$ & 0,2417 & 1,0000 & & & $C_{d a}$ \\
\hline$-0,3406$ & 0,1941 & $-0,8597$ & 0,6242 & 0,4522 & 0,3877 & $-0,9379$ & 0,4989 & 0,0203 & 0,3674 & 0,2294 & $-0,7892$ & $-0,3035$ & $-0,9145$ & $-0,6455$ & 0,1196 & $-0,2111$ & $-0,0883$ & $-0,5177$ & 0,1695 & 0,3742 & 0,4081 & $-0,3248$ & 1,0000 & & $C_{l a}$ \\
\hline 0,0701 & $-0,2462$ & $-0,6628$ & 0,6861 & 0,2609 & 0,2039 & 0,7481 & 0,5233 & $-0,1337$ & 0,5623 & 0,3928 & $-0,7217$ & $-0,5146$ & $-0,9328$ & $-0,5557$ & $-0,2426$ & $-0,1817$ & $-0,1096$ & $-0,6119$ & 0,2324 & 0,4081 & 0,5217 & $-0,5314$ & $-0,9265$ & 1,0000 & $N_{a s}$ \\
\hline
\end{tabular}

$$
\frac{x_{i j}-\overline{x_{j}}}{\sigma_{x_{j}}}-\text { statistical information normalization; } x_{i j}^{* T}-\text { transposed matrix Correlation matrix: } r=\frac{1}{n} x_{i j}^{*_{T} T} \cdot \frac{x_{i j}-\bar{x}_{j}}{\sigma_{x_{j}}}
$$

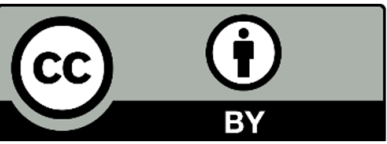

(c) 2021 by the authors; licensee Growing Science, Canada. This is an open access article distributed under the terms and conditions of the Creative Commons Attribution (CC-BY) license (http://creativecommons.org/licenses/by/4.0/) 